\title{
Histological features of CIN3 and their value in predicting invasive microinvasive squamous carcinoma
}

\author{
A I Al-Nafussi, D E Hughes
}

\begin{abstract}
Aims-To determine the histological features in CIN3 associated with or predictive of subsequent microinvasion.

Methods-The histological appearances of CIN3 accompanying 120 cases of microinvasive carcinoma of the uterine cervix were retrospectively studied. Major features were defined as those present in greater than $80 \%$ of cases of microinvasive carcinoma (MICA) and less than $10 \%$ of control cases of CIN3. One hundred cases of CIN3, 36 showing all, and 64 lacking all, of the major features associated with microinvasion, as defined in the retrospective study, were prospectively studied. Deeper levels were cut to exclude the presence of microinvasion in the original biopsy specimen and negative cases were followed up for a period of up to 18 months in order to assess rates of recurrence or progression.
\end{abstract}

Results-The major features identified in CIN3 associated with microinvasive carcinoma were extensive involvement of surface epithelium and deep endocervical crypts by expansile CIN3, luminal necrosis, and intraepithelial squamous maturation. Other features more commonly present in MICA associated CIN3 than in controls included frequent mitosis and apoptosis, pericryptal concentric fibroplasia, pericryptal inflammatory infiltrate, pronounced cellular pleomorphism, nuclear changes (distinct nucleoli and chromatin clearing), and the emergence of streams of darkly stained spindle cells orientated at right angles to the basement membrane. In the prospective study $83 \%$ of cases illustrating the major MICA associated features revealed evidence of MICA or frank invasion either on serial sections of the original biopsy or on subsequent biopsy. None of the 64 cases of CIN3 that lacked these features showed evidence of invasion on serial sections or on further follow up over 18 months.

Conclusions-The data strongly suggest that cases of CIN3 which have a higher probability of association with or rapid progression to invasive disease can be identified. When these features are present in a biopsy specimen of CIN3, serial sections should be performed to exclude the presence of microinvasion.
Closer clinical follow up of these patients may be needed.

(F Clin Pathol 1994;47:799-804)

Most cases of invasive squamous carcinoma of the cervix are thought to be preceded by the metaplasia-intraepithelial neoplasia (CIN) sequence. ${ }^{1-4}$ This has formed the basis for cervical screening programmes to detect the earlier stages of the disease in the hope of preventing invasive carcinoma and reducing the mortality from the disease. Most surgeons currently treat all cases of CIN with loop diathermy, laser, or cold coagulation therapy and follow them up regularly by cervical smears and colposcopic assessment. In spite of these measures some women will still have recurrence or progression of their disease. The reasons why some cases of CIN and in particular CIN3 recur or progress after treatment are currently uncertain. One of the reasons may be that the original lesion has not been fully excised, or a minute focus of microinvasive carcinoma (MICA) has been left behind or has not been detected in the biopsy specimen either due to misinterpretation or inadequate sampling. Another possibility is the existence of a biologically more aggressive subtype of CIN3. If this assumption is true it would be of paramount importance to identify the subtype. There is some indication, on the basis of cytogenetic studies, that CIN3 is heterogeneous in terms of risk of progression to cancer. ${ }^{56}$ On the basis of morphology alone, however, there is currently no recognised way of predicting which cases of CIN3 will progress. It is also controversial whether HPV associated CIN is biologically more sinister, ${ }^{7}$ in particular $\mathrm{CIN}$ containing HPV 18 rather than $16 .^{8}$

The Department of Pathology at Edinburgh University receives about 4000 colposcopic punch and loop biopsy specimens annually. Of these, $0.4 \%$ show MICA and $0.8 \%$ show invasive carcinoma. At weekly combined oncology/gynaecology/pathology meetings the management of all cases of invasive and microinvasive squamous carcinoma are discussed and current and previous histological samples reviewed.

On review of previous biopsy specimens from cases showing recurrence or progression and CIN3 adjacent to microinvasion, similar histological features were often noted. The aims of this study were to identify histological 
appearances in cases of CIN3 showing a significant association with microinvasion, and to test their utility in predicting subsequent microinvasion in a prospective series of cases of CIN3.

\section{Methods \\ PART I: RETROSPECTIVE STUDY OF FEATURES ASSOCIATED WITH MICROINVASIVE CARCINOMA One hundred and twenty cases of microinva- sive squamous carcinoma of the uterine cervix and 80 control cases of CIN3 without microinvasion were retrieved from the depart- mental surgical files made between 1988-1992. All were from loop excisions of cervix which had been fixed in Bouin's solu- tion and serially cut into six to 20 parallel blocks of about $3 \mathrm{~mm}$ in thickness. These were routinely processed and paraffin wax sections were stained with haematoxylin and eosin.}

\section{Microinvasive carcinoma}

The criteria used for the diagnosis of MICA were those proposed by the Society of Gynaecological Oncologists (SGO) in 1974 and modified in 1985: "MICA is defined as a lesion that invades the stroma to a depth of $3.0 \mathrm{~mm}$ or less, and in which there is no evidence of lymphatic space invasion". 910 SGO classification rather than FIGO was used because in a recent literature review, it was shown that the differrence in the incidence of lymph node metastasis for tumours 0.1 to $3.0 \mathrm{~mm}$ and for tumours 3.1 to $5.0 \mathrm{~mm}$ in depth is significant $(0.7 \% v 4.3 \%)$ and therefore a small number of women with FIGO stage 1a 2 (up to $5 \mathrm{~mm}$ in depth and $7 \mathrm{~mm}$ in width) will have tumour extension beyond the uterus. ${ }^{11}$

Foci of microinvasion were identified by squamoid differentiation in groups of cells separated from or protruding through the basement membrane of areas of CIN3 (fig 1). The depth of stromal invasion was measured using an ocular micrometer; the measurement was made between the deepest part of the invasive focus and the basement membrane of the overlying epithelium.

\section{Overlying/adjacent CIN3}

The following histological features were evaluated:

1 The extent of the lesion.

2 The proportion of crypts or surface affected by the lesion. Greater than about $25 \%$ of the glands or surface epithelium included in the specimen was considered to be extensive disease.

3 The complexity of the architecture of the lesion.

4 Expansion of the affected crypts or surface epithelium.

5 Secondary features.

6 The presence or absence of central (comedo-like) necrosis or inflammation.

7 The cell morphology.

8 The presence or absence of easily identifiable apoptosis or single cell dyskeratosis, the degree of pleomorphism and mitotic activity, and the nuclear pattern (presence of chromatin clearing or acquisition of nucleoli).

9 Appearance of adjacent stroma (fibrosis, inflammation).

The significance of the association of each of the above features with MICA evaluated using the $\chi^{2}$ test.
Figure 1 Early tongues of microinvasive squamous carcinoma (MICA) arising at the base of $a$ crypt involved and expanded by CIN3. Note also central necrosis within the CIN3 lesion $(A)$. The microinvasive tongues exhibit squamous differentiation and inflammatory response (B) (haematoxylin and eosin).

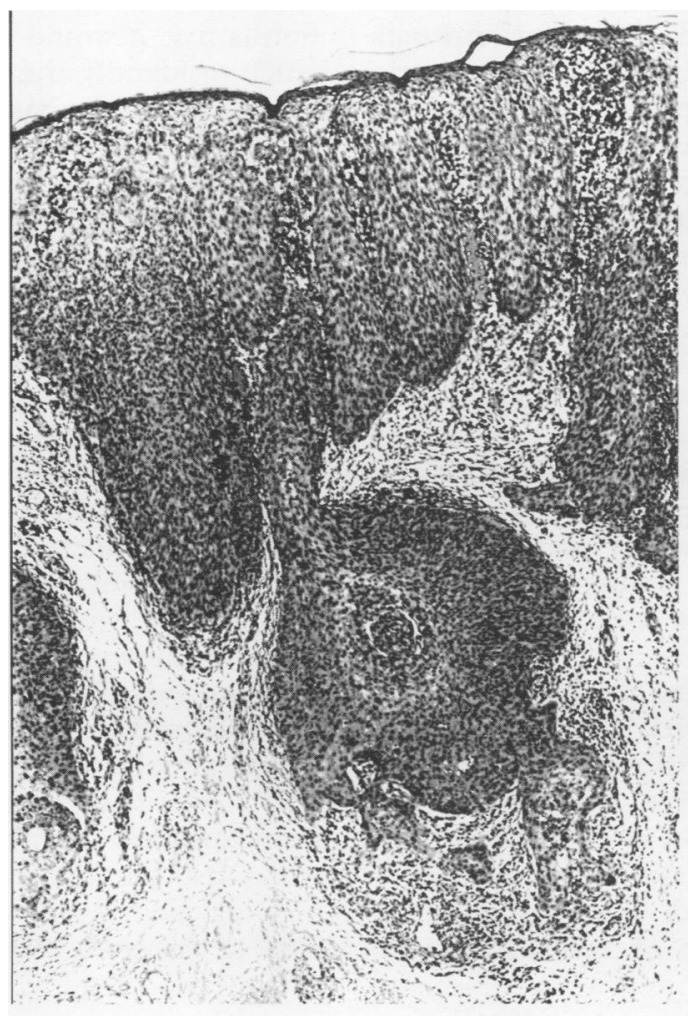

(A)

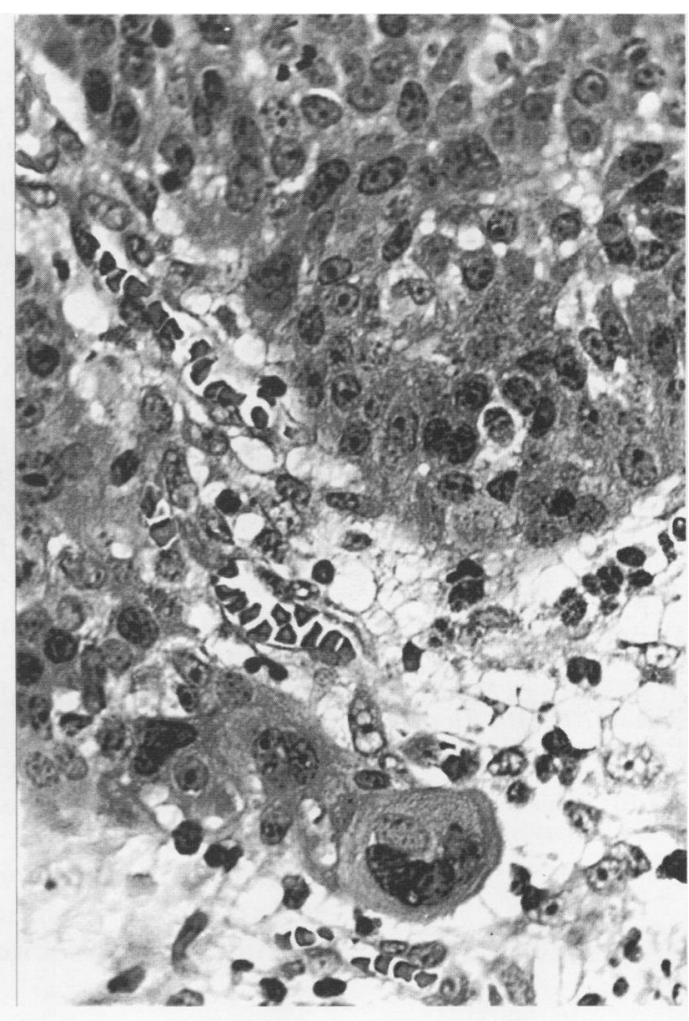

(B) 
Table 1 Incidence of various histological features found in association with microinvasive squamous carcinoma of cervix

\begin{tabular}{|c|c|c|}
\hline Histological features & $\begin{array}{l}\text { Control cases } \\
\text { (total } 80 \text { cases) }\end{array}$ & $\begin{array}{l}\text { CIN3 with MICA } \\
\text { (total } 120 \text { cases) }\end{array}$ \\
\hline Surface involvement only & $34(43 \%)$ & $9(7 \%)$ \\
\hline $\begin{array}{l}\text { Involvement of deepest } \\
\text { endocervical crypts present } \\
\text { in specimen }\end{array}$ & $1(1 \%)$ & $111(93 \%)$ \\
\hline $\begin{array}{l}\text { Irregular expansion of } \\
\text { involved surface/crypts }\end{array}$ & $5(6 \%)$ & $106(96 \%)$ \\
\hline Necrotic debris & $4(5 \%)$ & $99(82 \%)$ \\
\hline Intralesional maturation & $4(5 \%)$ & $105(87 \cdot 5 \%)$ \\
\hline Abnormal mitoses & $20(25 \%)$ & $53(44 \%)$ \\
\hline Apoptosis & $13(16 \%)$ & $101(84 \%)$ \\
\hline Dyskeratotic cells & $11(14 \%)$ & $67(55 \%)$ \\
\hline $\begin{array}{l}\text { Nuclear clearing with } \\
\text { prominent nucleoli }\end{array}$ & $6(8 \%)$ & $67(55 \%)$ \\
\hline $\begin{array}{l}\text { Pericryptal concentric } \\
\text { fibrosis }\end{array}$ & $8(10 \%)$ & $75(63 \%)$ \\
\hline $\begin{array}{l}\text { Pericryptal lymphocytic } \\
\text { infiltrate }\end{array}$ & $20(25 \%)$ & $92(77 \%)$ \\
\hline $\begin{array}{l}\text { Intralesional lymphocytic } \\
\text { infiltrate }\end{array}$ & $17(21 \%)$ & $78(65 \%)$ \\
\hline $\begin{array}{l}\text { Emergence of small dark } \\
\text { spindle cells }\end{array}$ & $12(15 \%)$ & $34(28 \%)$ \\
\hline
\end{tabular}

All of the above criteria were significantly associated with the presence of MICA $(p<0.001)$ except the emergence of darkly staining spindle cells $(p=0.05)$. In the case of restriction of disease to the surface epithelium, this association was significantly negative.

PART II: PROSPECTIVE STUDY OF PREDICTIVE VALUE OF FEATURES ASSOCIATED WITH INCIPIENT MICROINVASION

The predictive value of the criteria deduced in part I of this study (table 1) was assessed by examining cases which either displayed or lacked all of the major criteria (defined as criteria occurring in greater than $80 \%$ of cases of MICA and less than $10 \%$ of controls) listed in table 1. A total of 100 cases of CIN3 were assessed, 36 of which exhibited and 64 of which lacked the major criteria identified in part I of the study. These were selected from 250 cases of CIN3 received over a period of four months. Haematoxylin and eosin stained sections were studied, deeper levels were cut, and subsequent biopsy specimens (26/36), when present within a follow up period of one to 18 months, were reviewed for evidence of MICA or invasive carcinoma.

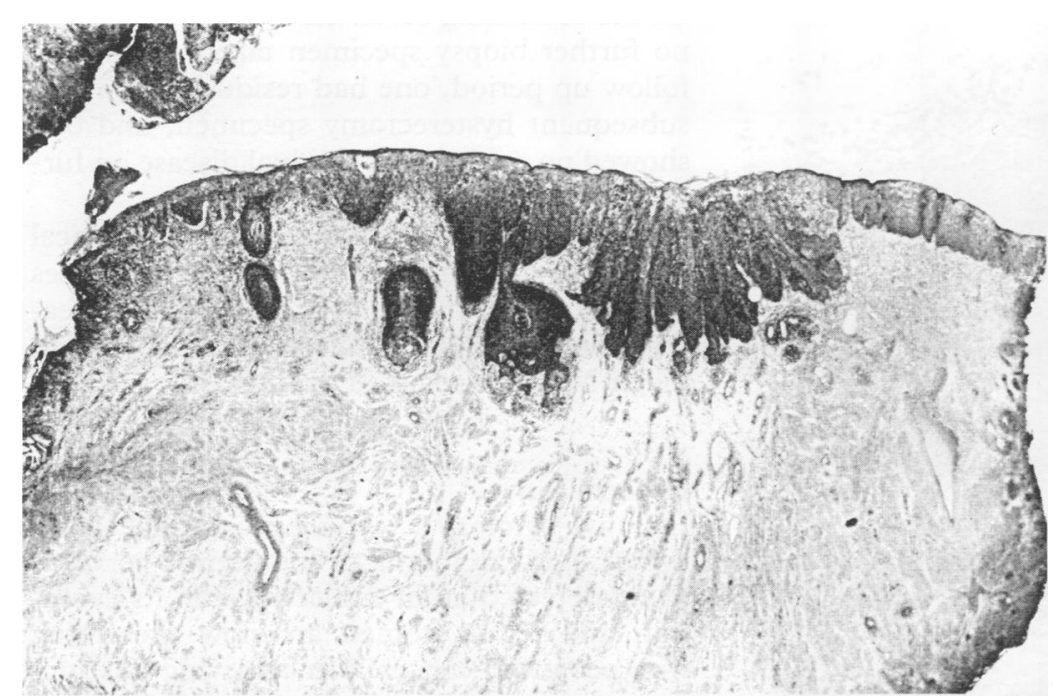

Figure 2 CIN3 involving surface epithelium and complex endocervical crypts. Note expansion and central necrosis of the involved crypts. Deeper levels confirmed the presence of very early invasion. Note also the intralesional maturation (haematoxylin and eosin).

\section{Results}

PART I: RETROSPECTIVE STUDY

Distribution of the lesion

Extensive involvement (more than $25 \%$ of epithelium) of both surface epithelium and endocervical crypts, including the deepest crypts present in the specimen was seen in $93 \%$ of cases of MICA and $1 \%$ of controls.

\section{Architecture of the involved epithelium}

In $96 \%$ of cases of MICA the involved crypts were distinctly expanded by the presence of CIN3, often with irregular bulging of their borders (fig 2). Similarly, the affected surface epithelium in these cases was irregularly expanded but to a lesser degree than the crypts. These features were present in $6 \%$ of controls.

\section{Necrosis}

Comedo-like central necrosis consisting of desquamated dyskeratotic cells admixed with polymorphs was seen within the lumen of the affected crypts with analogous necrosis of the surface epithelium in $82 \%$ of cases of MICA and $5 \%$ of controls (fig 3 ).

\section{Intralesional maturation}

Focal intraepithelial squamous maturation in the form of whorling, abortive squamous eddies, and cytoplasmic keratinisation was seen in $86 \%$ of cases of MICA and $5 \%$ of controls (figs 3 and 4 ).

\section{Cytological patterns}

The constituent cells exhibited mild, moderate, or severe cellular pleomorphism (fig 5). Some of the nuclei showed coarsening of the chromatin, focal clearing, and prominent nucleoli (55\% of cases of MICA, $8 \%$ of controls). Isolated single dyskeratotic cells were seen in $55 \%$ of cases of MICA and $14 \%$ of controls and were often associated with numerous apoptotic cells ( $84 \%$ of MICA and $16 \%$ of controls). Varying numbers of normal mitotic figures were present in all cases, and abnormal forms were seen in $44 \%$ of cases of MICA and $25 \%$ of controls. Finally there were streams of darkly stained, spindleshaped cells compressed inbetween the remaining epithelial cells and these seemed to be orientated vertically from the basement membrane towards the luminal surface (fig 6 ). These were seen more often in the invasive foci themselves but also in the overlying abnormal epithelium in $28 \%$ of cases of MICA. These cells were also identifiable in $15 \%$ of controls. Scattered intraepithelial lymphocytes were found in $65 \%$ of cases of MICA and $21 \%$ of controls.

\section{Adjacent stroma}

A concentric lamellar fibrosis was seen around the crypts in $63 \%$ of cases of MICA and $10 \%$ of controls (fig 7), and a moderate or dense lymphocytic infiltrate was shown in $77 \%$ of cases of MICA and $25 \%$ of controls.

PART II: PROSPECTIVE STUDY (table 2)

None of the 64 cases of CIN3 that lacked the 


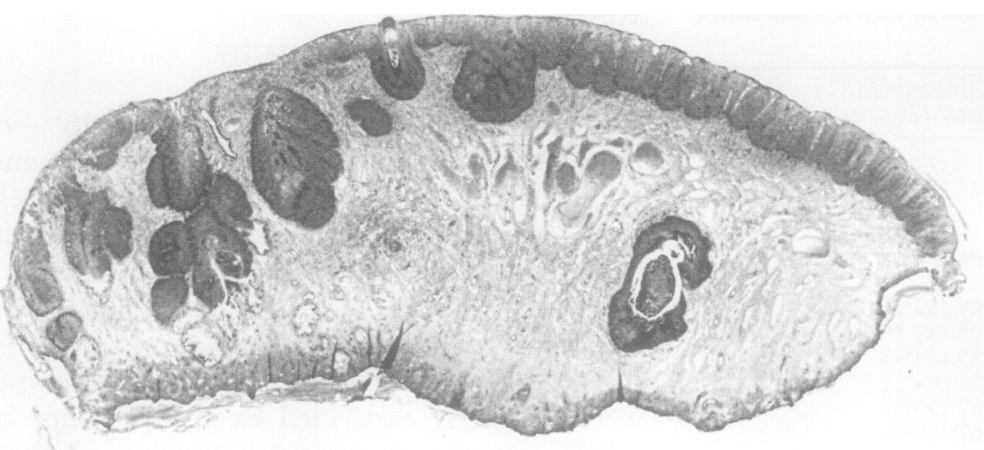

(A)

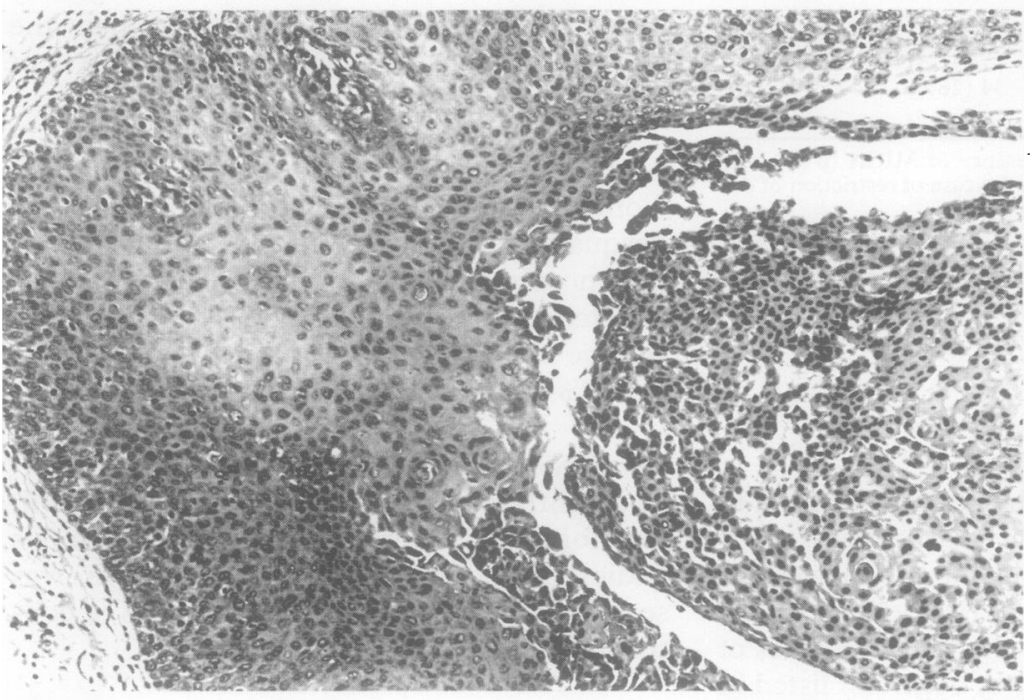

Figure 3 CIN3 involving and expanding endocervical crypt (A). Note intralesional squamous maturation and the central dyskeratotic necrosis (B) (haematoxylin and eosin).

Table 2 Comparison of prospectively studied cases showing or lacking major MICA associated features

\begin{tabular}{lcl}
\hline Incidence of features & $\begin{array}{l}\text { CIN3 with all major }(n=36) \\
\text { MICA associated features }\end{array}$ & $\begin{array}{l}\text { CIN3 with no major }(n=64) \\
\text { MICA associated features }\end{array}$ \\
\hline Coexistent MICA & $10(28 \%)$ & 0 \\
Recurrence as CIN3 & $1(3 \%)$ & 0 \\
Recurrence as MICA & $10(28 \%)$ & 0 \\
$\begin{array}{l}\text { Recurrence as } \\
\text { invasive carcinoma }\end{array}$ & $9(25 \%)$ & 0 \\
$\begin{array}{l}\text { Incomplete excision in } \\
\text { original biopsy specimen }\end{array}$ & $29(80 \%)$ & $33(52 \%)$ \\
\hline
\end{tabular}

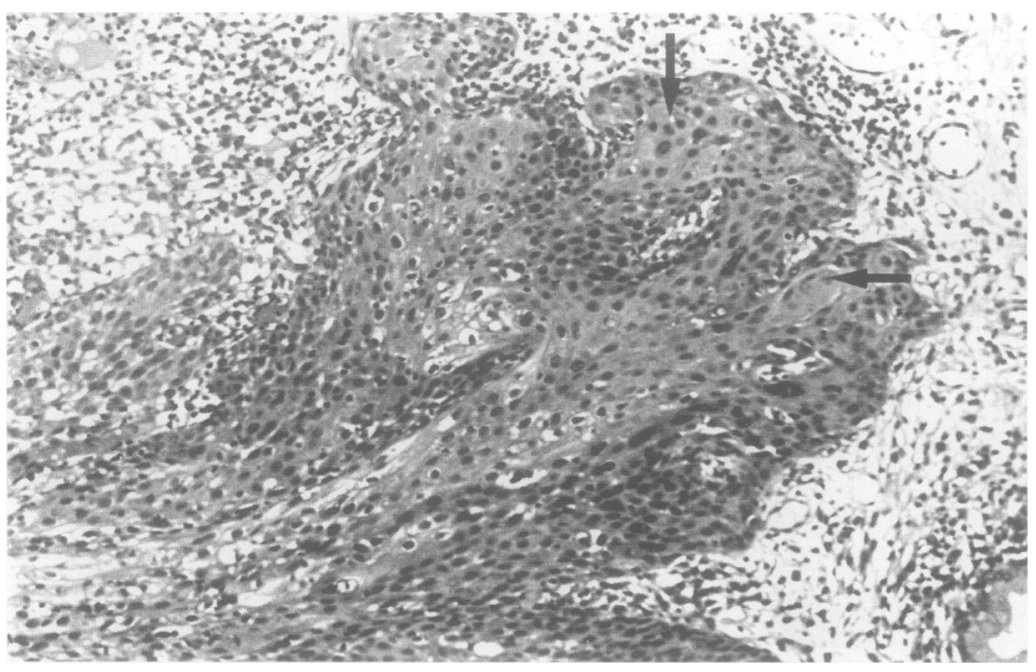

Figure 4 CIN3 lesion. Note intralesional squamous differentiation and early squamous eddies (arrow). A tongue of impending invasion is also seen (haematoxylin and eosin).

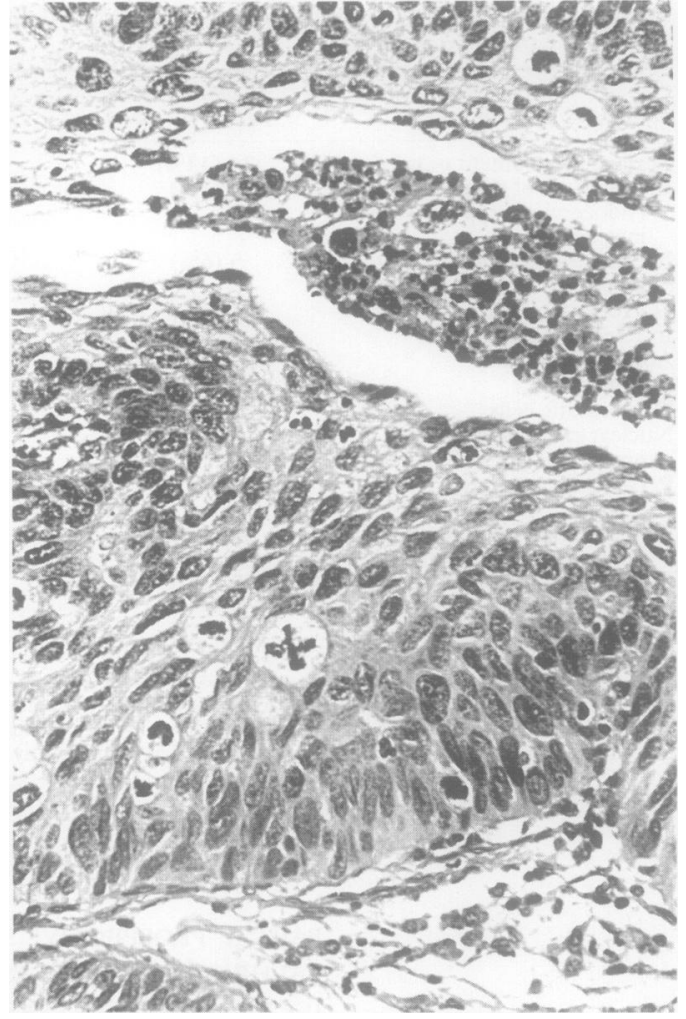

Figure 5 CIN3 involving endocervical crypt. Note cellular pleomorphism, apoptosis, abnormal mitoses and central necrosis (haematoxylin and eosin).

major criteria associated with microinvasion (in part I of this study) (table 1) showed evidence of microinvasion on deeper levels on further follow up. The major criteria were those present in over $80 \%$ of the MICA cases and under $10 \%$ of controls (involvement of both surface and deep crypt epithelium, expansion of involved glands, central necrosis and intralesional maturation).

Of the $36 \mathrm{CIN} 3$ exhibiting all of the above major criteria, $20(55 \%)$ showed evidence of MICA (17 in further follow up biopsy specimens and $10(28 \%)$ on deeper levels of the original biopsy specimen) and nine cases showed frank invasion (on follow up biopsy). Of the remaining seven cases $(19 \%)$, five had no further biopsy specimen taken during the follow up period, one had residual CIN3 in a subsequent hysterectomy specimen, and one showed no evidence of residual disease on further loop excision biopsy.

CIN3 had extended into the endocervical resection margin in $80 \%$ of the 36 cases exhibiting the major MICA associated features and in $51 \%$ of the 64 cases lacking all major MICA associated features.

\section{Discussion}

Effective cytology screening programmes have meant that carcinoma of the uterine cervix is being detected at an earlier stage in its evolution and fewer women are now presenting with advanced cancer. ${ }^{12}$ In achieving this success, the screening programme has led to a huge increase in surgical interventions, many of which may arguably represent overtreat- 


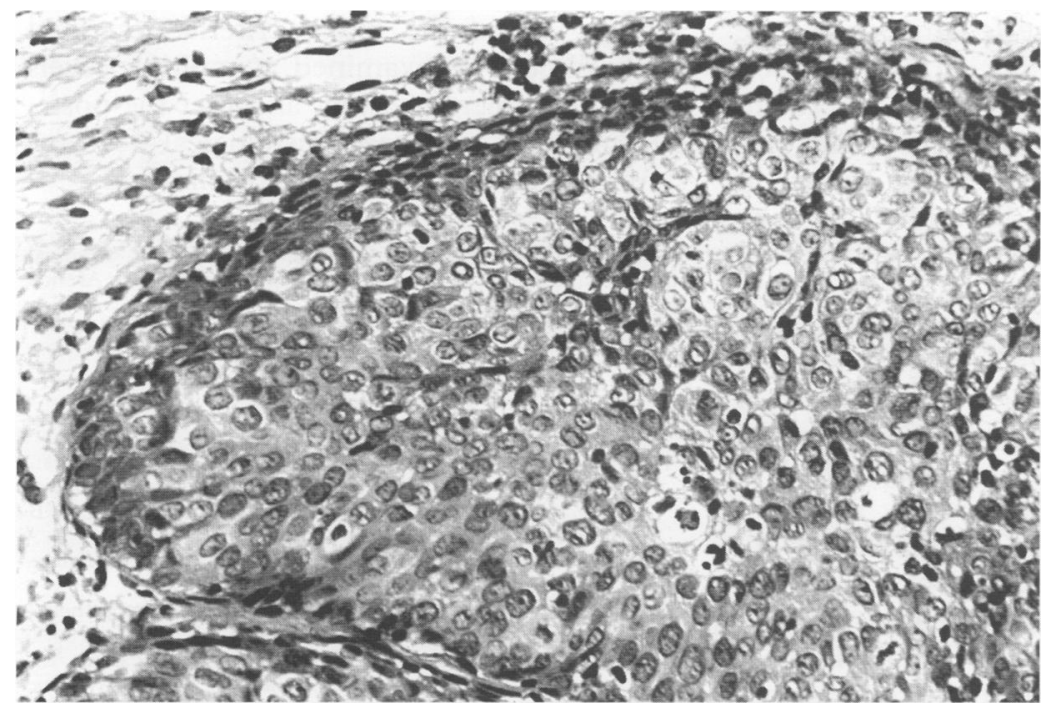

Figure 6 CIN3 showing pericryptal condensation of cells and the emergence of small dark spindle cells traversing from the basal layers towards the crypt centre (haematoxylin and eosin).

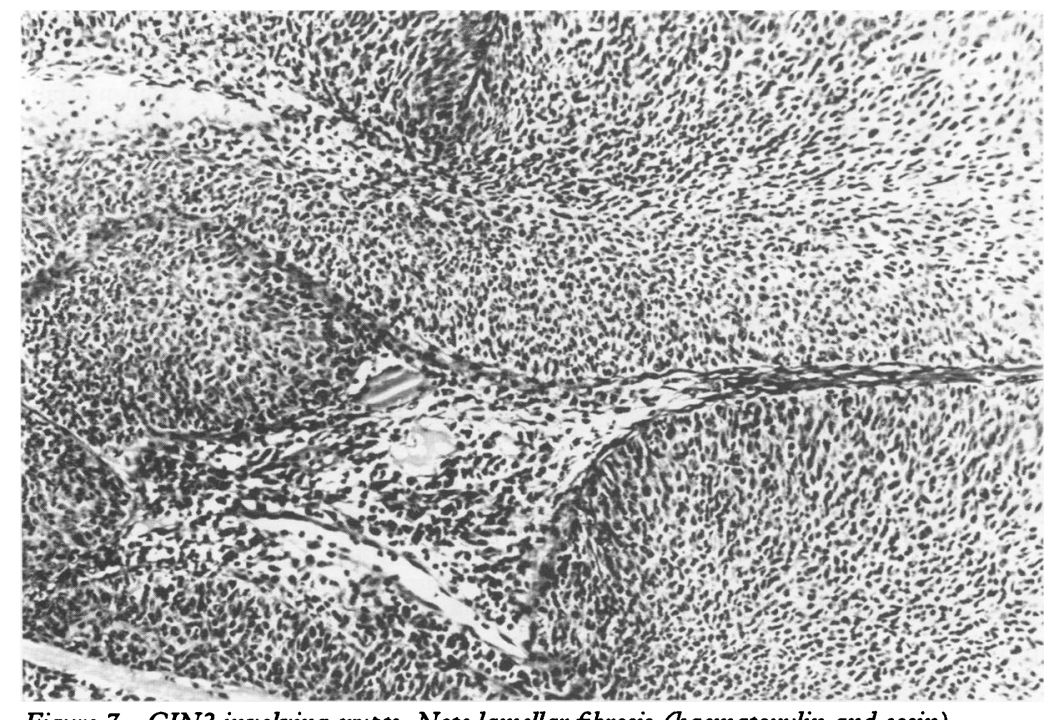

Figure 7 CIN3 involving crypts. Note lamellar fibrosis (haematoxylin and eosin).

ment; yet cases of invasive squamous carcinoma still occur in women who have been regularly screened. Until now it has not been considered possible to distinguish cases of CIN which have a higher risk of rapid progression to invasive disease. If such a distinction could reliably be made on histological grounds, clinical management protocols could be adjusted accordingly, with benefits to both patients with "high risk" or "low risk" disease.

In this study we identified several histological criteria which are present in most (over $80 \%$ ) of cases of CIN3 accompanying MICA and in a minority of control cases (under $10 \%$ ), which had predicted aggressive behaviour in prospectively collected cases. The major predictive criteria (table 1) were extensive involvement of both surface and deep endocervical crypts, expansion of the crypts by CIN3, comedo-like central necrosis, and intralesional squamous maturation. Increasing involvement of the endocervical crypts seems to occur with progression of
CIN. Anderson and Hartley ${ }^{13}$ found that $88.6 \%$ of CIN3 had some crypt involvement; Abdul-Karim et al found that the higher the grade of the CIN the greater the extent of the surface and crypt involvement, ${ }^{14}$ and Demopoulos et al have shown that deep endocervical gland involvement by $\mathrm{CIN} 3$ is a highly significant predictor of residual or recurrent disease. ${ }^{15}$ Another important feature highlighted by the present study was distension or expansion of the involved endocervical crypts or surface epithelium. The frequent finding of comedo-like central necrosis may represent a further progression of this process.

Changes in the cytological appearance of CIN3 adjacent to microinvasive carcinoma have been reported before. ${ }^{16}{ }^{17}$ These include: islands of well differentiated squamous cells present at all levels of the epithelium; disorganised cellular polarity; cellular pleomorphism; presence of nucleoli in some cells; frequent pyknosis; and individual cell keratinisation. All of these features were confirmed in the present study, but squamous maturation (either in the form of keratinisation or squamous eddies) was found to be the most frequent change. The other cytological changes described above (termed minor criteria in table 1) were frequently present in cases with microinvasion, but were not found to have predictive value in the prospective study.

Whether these changes precede or develop simultaneously with MICA cannot be ascertained with certainty by this study. If they precede MICA this is of great importance, as their presence in CIN3 may indicate incipient invasion. In the second part of this study follow up biopsy specimens from the cases of CIN3 exhibiting all of the major criteria showed MICA in $48 \%$ and frankly invasive carcinoma in $23 \%$. One third of the remaining $29 \%$ illustrated foci of MICA on serial sections of the original biopsy specimen and the remainder showed no evidence of invasion either on deeper levels or on subsequent biopsy specimens. This lack of progression may represent adequate treatment, rather than lack of aggressive potential.

None of the cases of CIN3 selected as a control group (lacking any' of the major criteria) progressed during the period of the study. Interestingly, retrospective examination of the surgical files over the period of the study showed that none of the surgically treated cases of CIN3 received by our department but not included in this study had progressed, despite CIN3 extending into the endocervical resection margin in $51 \%$ of these cases. This suggests that incompleteness of excision may not be the only factor involved in the high rate of recurrence or progression seen in the cases with the major MICA associated features.

The results of this study suggest that there are certain histological features which when present in CIN3 predict a greater risk of progression to invasion, compared with cases lacking these features. We do not propose readoption of the former division of CIN3 into severe dysplasia and carcinoma in situ on this basis, but we feel that when present, the 
possible meaning of these features should be communicated to the clinician. The reason for this is twofold. Firstly, even with thorough sampling, it is possible to miss foci of microinvasion, as has been coincidentally shown in the course of this study. Secondly, the high risk category of CIN3 involves endocervical glands more extensively and is therefore more likely to be incompletely excised during standard loop excision, as has been suggested by the study of Demopoulos et al. ${ }^{15}$ Clearly, if residual disease of this type progresses more rapidly or is already associated with MICA at the time of surgery, recurrence as more advanced invasive disease (as happened in six cases in this study) is a serious possibility.

We therefore feel that there is a case for using terminology such as "CIN3 with features suggestive of incipient microinvasion," or "CIN3 with features associated with microinvasion," in reporting cases of CIN3 showing the high risk pattern described in this study. This would at least instil in the clinician's mind a requirement for closer follow up (perhaps with endocervical brush cytology) or further excision, particularly if the completeness of the original excision was in doubt.

In conclusion, this study highlights the potential importance of recognising certain features in CIN3 which suggest incipient microinvasion. The major criteria identified were: extensive, expansile involvement of both surface and crypt epithelium, including the deepest crypts present in the specimen; central dyskeratotic necrosis; and intralesional squamous maturation. Other features frequently present in these cases were dyskeratosis and apoptosis, pericryptal lymphocytic infiltration, and fibrolammelar fibrosis, but these features were not found to have predictive value. Whether the high risk cases represent a biologically distinct subset (for example, with relation to human papillomavirus infection) or simply more advanced disease will require further elucidation. In practice, however, we recommend that cases showing all of the major criteria described above should be examined at multiple levels to exclude microinvasion, and that the possible meaning of these histological features should be communicated to the clinician.

We thank Bill Hopkins of the Department of Medical Illustration for help in preparing the figures and Mark Arends for his comments on the manuscript.

1 Burghardt E. Transition to invasive growth. In: Friedman EA, ed. Early histological diagnosis of cervical cancer. Major problems in obstetrics and gynaecology. Philadelphia: WB Saunders, 1973:289.

2 Richart RM. Natural history of cervical intraepithelial neoplasia. Clin Obstet Gynaecol 1967;10:748-84.

3 Buckley CH, Butler EB, Fox H. Cervical intraepithelial neoplasia. $\mathcal{F}$ Clin Pathol 1982;35:1-13.

4 Anderson MC. The natural history of cervical cancer. In: Anderson MC. The natural history of cervical cancer. In:
Anderson MC, ed. Female reproductive system. Systemic pathology Vol 6. 3rd edn. Edinburgh: Churchill Livingstone, 1991

5 Kirkland JA, Stanley MA, Cellier K. Comparative study of histologic and chromosomal abnormalities in cervical neoplasia. Cancer 1967;20:1934-52.

6 Kirkland JA. The study of chromosomes in cervical neoplasia. Obstet Gynaecol Surveys 1969;24:784-94.

7 Ambros RA, Kurman RJ. Current concepts in the relationship of human papillomavirus infection to the pathogenesis and classification of precancerous squamous lesions of the uterine cervix. Semin Diagn Pathol 1990;7:158-72.

8 Arends MJ, Donaldson YK, Duvall E, et al. Human papilArends MJ, Donaldson YK, Duvall E, et al. Human papil-
lomavirus type 18 associates with more advanced cervilomavirus type 18 associates with more advanced cervi-
cal neoplasia than human papillomavirus type 16 . Hum cal neoplasia than hum
Pathol 1993;24:432-7.

9 Tsukamoto N, Kaku T, Matsukuma K, et al. The problem of stage 1a (Figo 1985) Carcinoma of the uterine cervix. Gynaecol Oncol 1989;34:1-6.

10 Javaheri G. Microinvasive carcinoma of the uterine cervix. Int $\mathcal{F}$ Gynaecol Obstet 1978;16:106-14.

11 Robert ME, Fu YS. Squamous cell carcinoma of the uterine cervix-A review with emphasis on prognostic factors and unusual variants. Semin Diagn Pathol 1990;7:173-89.

12 Benedet JL, Anderson GH, Matisic JP. A comprehensive program for cervical cancer detection and management. program for cervical cancer detection
$A m \ngtr$ Obstet Gynecol 1992;166:1254-9.

13 Anderson MC, Hartley RB. Cervical crypt involvement by intraepithelial neoplasia. Obstet Gynaecol 1980;55: 546-50.

14 Abdul-Karim FW, Fu YS, Reagan JW, Wentz WB. Morphometric study of intraepithelial neoplasia of the uterine cervix. Obstet Gynaecol 1982;60:210-4.

15 Demopoulos Rita I, Horowitz Laurie F, Vamvakas Eleftherois C. Endocervical gland involvement by cervical intraepithelial neoplasia grade III. Cancer 1991;68: 1932-6.

$16 \mathrm{Ng}$ ABP, Reagan JW. Microinvasive carcinoma of the uterine cervix. Am ₹ Clin Pathol 1969;52:511-29.

17 Sedlis A, Sol S, Tsukada Y, et al. Microinvasive carcinoma of the uterine cervix: a clinical-pathologic study. $A m \mathcal{F}$ Obstet Gynecol 1979;133:64-74. 